\title{
Antimicrobial susceptibilities of Listeria monocytogenes isolated from the imported and the domestic foods in Japan
}

\author{
Yumiko Okada $^{1,}$, , Shuko Monden ${ }^{1}$, Hodaka Suzuki ${ }^{1}$, Akiko Nakama ${ }^{2}$, Miki Ida ${ }^{2}$, Shizunobu Igimi ${ }^{1}$ \\ ${ }^{1}$ Division of Biomedical Food Research, National Institute of Health Sciences, 1-18-1, Kamiyoga, Setagaya-ku, Tokyo 158-8501, Japan \\ ${ }^{2}$ Department of Microbiology, Tokyo Metropolitan Institute of Public Health, 3-24-1 Hyakunin-cho, Shinjuku-ku, Tokyo 169-0073, Japan
}

\author{
Email address: \\ yokada@nihs.go.jp (Y. Okada)
}

\section{To cite this article:}

Yumiko Okada, Shuko Monden, Hodaka Suzuki, Akiko Nakama, Miki Ida, Shizunobu Igimi. Antimicrobial Susceptibilities of Listeria monocytogenes Isolated from the Imported and the Domestic Foods in Japan. Journal of Food and Nutrition Sciences. Special Issue: Food Processing and Food Quality. Vol. 3, No. 1-2, 2015, pp. 70-73. doi: 10.11648/j.jfns.s.2015030102.23

\begin{abstract}
In vitro antimicrobial susceptibility of Listeria monocytogenes isolated from the imported and the domestic foods in Japan was determined by plate dilution method. Eleven isolates from domestic meat, meat products, liver, seafood and environment, and 16 isolates from imported meat and meat products were examined their susceptibilities against ampicillin, chloramphenicol, enrofloxacin, erythromycin, gentamicin, kanamycin, penicillin and tetracycline. All of the isolates except the one isolate from domestic scallop were susceptible to all the antibiotics tested. Only 1 isolate showed resistance to kanamycin and gentamicin. The minimum inhibitory concentration (MIC) for $50 \%$ of the strains and the MIC for $90 \%$ of the strains were comparable between the imported and the domestic food origins. These results suggest there were less differences of antimicrobial susceptibility between the two origins of Listeria isolates.
\end{abstract}

Keywords: Listeria monocytogenes, Antibiotic Susceptibility

\section{Introduction}

Listeriosis, a severe-infectious disease caused by Listeria monocytogenes, is known to transmit to human via contaminated foods. In contrast to the situation in the North America or EU countries, the outbreaks of listeriosis have occurred in every few years, there is only one outbreak officially recognized in Japan to the date (Makino, 2006). As the sporadic cases, however, the incidence rates in Japan were estimated as 0.65 cases per million in 1996-2002 (Okutani, 2004a) and 1.0-1.6 per million in 2008-2011 (Yamane, 2012). These numbers are comparable to those in European countries (EC). The reason that the frequency of outbreak in Japan is very low compared with those of the European countries and United States remains uncertain. L. monocytogenes is isolated from many types of foods in Japan, and their levels of contamination are similar to those in the other countries (Okutani, 2004b). Self-sufficiency rate in food is about $40 \%$ in Japan, and many types of food are imported. Non-cooked meat products like raw ham and the dairy products like fresh cheese from Europe and the other countries are popular in Japan, and the amount of import of these foods is continuously increased. However, these foods are known to be often contaminated by L. monocytogenes.

Antimicrobial drugs such as ampicillin or gentamicin are used commonly for the treatment of listeriosis, although, there are many reports about antibiotics resistant strains of $L$. monocytogenes from Europe, America and the other countries. In this study, we determined the antimicrobial susceptibility of L. monocytogenes isolated from imported and domestic foods in Japan.

\section{Materials and Methods}

\subsection{Bacterial Strains and Media}

Eleven isolates from domestic meat, meat products, liver and fishery products, and 16 isolates of $L$. monocytogenes from imported meat and meat products were used for examination of their antibiotic susceptibilities (Table 1).

These were isolated in Japan from 2000 to 2008. The raw ham and salami samples were imported from Spain, and the chicken meat samples are imported from Brasil. $L$. monocytogenes EGD (serotype 1/2a) and Enterococcus faecalis ATCC29212 (provided from Riken Bioresource Center, Japan) were used as control.

All of the isolates were stocked in Brain Heart Infusion 
(BHI) broth (Difco) with $20 \%$ glycerol at $-80^{\circ} \mathrm{C}$ until used. Bacterial cells were grown in $\mathrm{BHI}$ broth at $37^{\circ} \mathrm{C}$ for $24 \mathrm{~h}$, and diluted to $1 / 10$ with saline for antibiotic resistance tests. Muller-Hinton agar (Difco) was used for the plate dilution method.

\subsection{Antibiotics Susceptibility Test}

All strains were tested their susceptibilities against 8 types of antibiotics; ampicillin (ABPC; Wako Chemicals, Tokyo, Japan), chloramphenicol (CM; Wako), enrofloxacin (ERFX; Sigma, St. Louis, USA), erythromycin (EM; Sigma), gentamicin (GM; Wako), kanamycin (KM; Wako), penicillin (PN; Wako) and tetracycline (TC; Wako) by standard plate dilution method as in the previous study (Okada, 2011). All antibiotics were used in two-fold serial dilution at concentrations from 0.25 to $128 \mu \mathrm{g} / \mathrm{ml}$. The inoculation of the bacterial cells on Muller-Hinton agar was performed using
MicroPlanter MIT-P (SAKUMA, Tokyo, Japan) according to manufacturer's instruction. All plates were incubated at $37^{\circ} \mathrm{C}$. The formation of colonies was observed at $48 \mathrm{~h}$ after inoculation, and the minimum inhibitory concentration (MIC), the MIC for $50 \%$ of the strains $\left(\mathrm{MIC}_{50}\right)$, and the MIC for $90 \%$ of the strains $\left(\mathrm{MIC}_{90}\right)$ were determined for each antibiotic. The breakpoints for the susceptibility of L. monocytogenes to ABPC and PN were followed by the Clinical and Laboratory Standards Institute (CLSI) guideline, M31-A3 (CLSI, 2008). For the antibiotics which had bimodal MIC distributions, the microbiological breakpoints were applied as well as the report of the Japanese Veterinary Antimicrobial Resistance Monitoring System (Takahashi, 2006). The microbiological breakpoint is defined as the intermediate MIC between the 2 peak distributions. For the antibiotics which had monomodal MIC distributions, the breakpoints were not determined.

Table 1. L. monocytogenes strains used in this study.

\begin{tabular}{|c|c|c|c|c|}
\hline Origin & Type of foods & Number of isolates & Isolated year & Serotype \\
\hline \multirow[t]{8}{*}{ Domestic foods } & Beef liver & 1 & 2000 & $4 \mathrm{~b}$ \\
\hline & Pork liver & 2 & 2000 & $4 b$ \\
\hline & Beef meat & 3 & 2000 & $1 / 2 b, 4 b$ \\
\hline & Pork meat & 1 & 2000 & $1 / 2 b$ \\
\hline & Chicken sasami & 1 & 2000 & $1 / 2 b$ \\
\hline & Pork cotlet & 1 & 2008 & $1 / 2 \mathrm{a}$ \\
\hline & Scallop & 1 & 2008 & $4 b$ \\
\hline & Total & 11 & & \\
\hline \multirow[t]{4}{*}{ Imported foods } & Raw ham & 2 & 2007 & $1 / 2 \mathrm{a}, 1 / 2 \mathrm{c}$ \\
\hline & Salami & 4 & 2007 & $1 / 2 \mathrm{a}, 1 / 2 \mathrm{~b}, 1 / 2 \mathrm{c}, 3 \mathrm{~b}$ \\
\hline & Chicken meat & 10 & 2006-2008 & $1 / 2 a, 1 / 2 c, 3 a, 4 b$ \\
\hline & Total & 16 & & \\
\hline
\end{tabular}

\section{Results}

\subsection{Antimicrobial Susceptibility of L. monocytogenes from Imported and Domestic Foods}

MIC against ABPC and PN of the all isolates in this study were $2 \mu \mathrm{g} / \mathrm{mL}$ or below (Table 2).

Table 2. MIC distributions, $M I C_{50}$ and $M I C_{90}$ of L. monocytogenes isolates.

\begin{tabular}{|c|c|c|c|c|c|c|c|c|c|c|c|c|}
\hline \multirow{2}{*}{ Antibiotic } & \multirow{2}{*}{ Origin $^{a}$} & \multicolumn{9}{|c|}{ Number of strains with MIC $(\mu \mathrm{g} / \mathrm{ml})$ of } & \multicolumn{2}{|l|}{$(\mu \mathrm{g} / \mathrm{ml})$} \\
\hline & & 0.25 & 0.5 & 1 & 2 & 4 & 8 & 16 & 32 & 64 & $\mathrm{MIC}_{50}$ & $\mathrm{MIC}_{90}$ \\
\hline \multirow{2}{*}{ ABPC } & $\mathrm{D}$ & & & 7 & 4 & & & & & & 1 & 2 \\
\hline & I & & & 14 & 2 & & & & & & 1 & 2 \\
\hline \multirow{2}{*}{$\mathrm{CP}$} & $\mathrm{D}$ & & & & & & 1 & 10 & & & 16 & 16 \\
\hline & I & & & & & & 9 & 7 & & & 8 & 16 \\
\hline \multirow{2}{*}{ EM } & $\mathrm{D}$ & & 9 & 2 & & & & & & & 0.5 & 1 \\
\hline & I & & 14 & 2 & & & & & & & 0.5 & 1 \\
\hline \multirow{2}{*}{ ERFX } & D & & 4 & 6 & 1 & & & & & & 1 & 1 \\
\hline & I & & 4 & 12 & & & & & & & 1 & 1 \\
\hline \multirow{2}{*}{ GM } & D & & 6 & 4 & & $1^{\mathrm{b}}$ & & & & & 0.5 & 1 \\
\hline & I & 6 & 7 & 3 & & & & & & & 0.5 & 1 \\
\hline \multirow{2}{*}{ KM } & D & & & & 7 & 3 & & $1^{\mathrm{b}}$ & & & 2 & 4 \\
\hline & I & & & 2 & 13 & 1 & & & & & 2 & 2 \\
\hline $\mathrm{PN}$ & D & 10 & 1 & & & & & & & & 0.25 & 0.25 \\
\hline \multirow{2}{*}{ TE } & D & & & 1 & 10 & & & & & & 2 & 2 \\
\hline & I & & & 4 & 10 & 2 & & & & & 2 & 4 \\
\hline
\end{tabular}

${ }^{\text {a }} \mathrm{D}$ : domestic, I: imported

${ }^{\mathrm{b}}$ Resistance 
CLSI defined that the MIC of $\leqq 2 \mu \mathrm{g} / \mathrm{mL}$ is susceptible in Listeria spp., and the MIC of $>2 \mu \mathrm{g} / \mathrm{mL}$ should be described as non-susceptible (CLSI). In accordance with this guideline, all isolates were determined as susceptible to $\mathrm{ABPC}$ and $\mathrm{PN}$. The MIC distributions of CP $(8-16 \mu \mathrm{g} / \mathrm{m} l)$, EM $(0.5-1 \mu \mathrm{g} / \mathrm{m} l)$, ERFX $(0.5-1 \mu \mathrm{g} / \mathrm{m} l)$, and TE $(1-4 \mu \mathrm{g} / \mathrm{m} l)$ were monomodal, suggesting that all the isolates were susceptible to these antibiotics (Table2). The MIC distributions of GM and KM were bimodal, and the microbiological breakpoint was determined as 2 and $8 \mu \mathrm{g} / \mathrm{ml}$, respectively (Table 2). One isolate from a domestic scallop in 2008 was resistant to GM and $\mathrm{KM}$ and their MICs were 4 and $16 \mu \mathrm{g} / \mathrm{ml}$, respectively. In all antibiotics, there were no differences of $\mathrm{MIC}_{50}$ and $\mathrm{MIC}_{90}$ between the imported and the domestic foods.

\section{Discussion}

From the result in this study, L. monocytogenes strains isolated from the imported and the domestic foods in Japan were mainly susceptible to the major antibiotics. In our previous study about the resistance against 16 types of antibiotic in 101 isolates from patients and 100 isolates from foods and environment, we found that only 1 isolate from patient was resistant to oxytetracyclin and tetracyclin (Okada, 2011). This result supports that the listerial resistant rates to antibiotics in Japan are at low level basically. However, 1 isolate from scallop was found to be resistant against GM and KM in this study. GM is often used for the treatment of human listeriosis, therefore, the emergence of the resistant isolates can be threat for public health. In another study in Japan, one isolate from the feces of patient cow was resistant to GM (Hara, 1983). GM-resistant isolates were isolated from several countries; from $60.9 \%(14 / 23)$ of dairy products in Spain (Rota, 1996), 42.9\% (3/7) of milk in India (Bhilegaonkar, 1997), 2\% (1/52) of cancer patients in USA (Safdar, 2003), 4.6\% (2/43) of foods in Poland (Majczyna, 2006). Zamora et al. described that $15 \%$ (3 of 20) of clinical isolates were resistant to GM in Costa Rica (Zamora, 2006). In Mexico, Rodas-Suarez et al. researched fish and seawater and found the $2.3 \%$ ( 1 of 68 ) of isolates were GM-resistant (Rodas-Suarez, 2006). In Canada, 31.8\% (14/44) of isolates from the feces of dairy cow and isolates from the feces of wildlife animals were resistant to GM (Lyautey, 2007). These indicate that the GM-resistant isolates were mainly found from dairy products, clinical specimen and seafood. It suggests the possibility that the frequency and/or the amount of GM used in medical practices and at dairy farms might be related with the appearance of GM-resistant isolates. Only one isolate from seafood was examined, therefore, further research which subject to seafood and its products should be done.

The result in this study shows that the continuous survey about the antibiotic susceptibility in $L$. monocytogenes isolates is important to secure the trend of antibiotics resistance for the essential treatment of listeriosis.

\section{Acknowledgement}

This study was supported by Health and Labour Sciences Research Grants, Research on Food Safety, from the Ministry of Health, Labour and Welfare of Japan (H24-shokuhinippan-007).

\section{References}

[1] Bhilegaonkar, K. N., Kulshrestha, S. B., Kapoor, K. N., Kumar, A., Agarwal, R. K., \& Singh, B. R. (1997). Isolation of Listeria monocytogenes from milk. Journal of Food Sciences and Technology, 34, 248-250.

[2] Clinical and Laboratory Standards Institute. (2008). Performance Standards for Antimicrobial Disk and Diliution Susceptibility Tests for Bacteria Isolated from Animals; Approved Standard- Third Edition. M31-A3, vol. 28, No. 8.

[3] EC. "Listeriosis. Incidence per 100,000 of population" [Internet]. [cited 2014 Jul 16]. Available from: $\mathrm{http} / /$ ec.europa.eu/health/ph information/dissemination/echi/ docs/listeriosis_en.pdf

[4] Hara, F., Ueno, H., Shiraishi, T., Okada, Y., \& Ohfuku, S. (1983). Listeria monocytogenes associated with premature death of a bovine fetus. Journal of Japanese Veterinary Medical Association, 36, 205-209.

[5] Lyautey, E., Hartmann, A., Pagotto, F., Tyler, K., Lapen, D. R., Wilkes, G., Piveteau, P., Rieu, A., Robertson, W. J., Medeiros, D. T., Edge, T. A., Gannon, V. \& Topp, E. (2007). Charasteristics and frequency of detection of fecal Listeria monocytogenes shed by livestock, wildlife, and humans. Canadian Journal of Microbiology, 53, 1158-1167.

[6] Makino, S. I., Kawamoto, K., Takeshi, K., Okada, Y., Yamasaki, M., \& Igimi, S. (2006). An outbreak of food-borne listeriosis due to cheese in Japan, during 2001. International Journal of Food Microbiology, 104, 189-196.

[7] Majczyna, D., \& Białasiewicz, D. (2006). Characteristic of Listeria spp. bacteria isolated from food products. Medycyna doświadczalna i mikrobiologia, 58, 119-126.

[8] Okada, Y., Okutani, A., Suzuki, H., Asakura, H., Monden, S., Nakama, A., Maruyama, T., \& Igimi, S. (2011). Antimicrobial susceptibilities of Listeria monocytogenes isolated in Japan. Journal of Veteterinary Medical Sciences, 73, 1681-1684.

[9] Okutani, A., Okada, Y., Yamamoto, S., \& Igimi, S. (2004). Nationwide survey of human Listeria monocytogenes infection in Japan.” Epidemiology and Infection, 132, 769-772.

[10] Okutani, A., Okada, Y., Yamamoto, S., \& Igimi, S. (2004). Overview of Listeria monocytogenes contamination in Japan. International Journal of Food Microbiology, 93, 131-140.

[11] Rodus-Suárez, O. R., Flores-Pedroche, J. F., Betancourt-Rule, J. M., Quiñones-Ramírez, E. I., \& Vázquez-Salinas, C. (2006). Occurrence and antibiotics sensitivity of Listeria monocytogenes strains isolated from oysters, fish, and estuarine water. Applied and Environmental Microbiology, 72, 7410-7412. 
[12] Rota, C., Yangüela, J., Blanco, D., Carramiñana, J. J., Ariño, A., \& Herrera, A. (1996), High prevalence of multiple resistance to antibiotics in 144 Listeria isolates from spanish dairy and meat products. Journal of Food Protection, 59, 938-943.

[13] Safdar, A. \& Armstrong, D. (2003). Antimicrobial activities against 84 Listeria monocytogenes isolates from patients with systemic listeriosis at a comprehensive cancer center. Journal of Clinical Microbiology, 41, 483-485.

[14] Takahashi, T., Asai, T., Kojima, A., Harada, K., Ishikawa, K., Morioka, A., Kijima, M., \& Tamura, Y. (2006). Present situation of national surveillance of antimicrobial resistance in bacteria isolated from farm animals in Japan and correspondence to the issue. Journal of Japanese Association of Infectious Diseases, 80, 185-195.

[15] Yamane, K., Suzuki, R. \& Shibayama, K. (2012). Kouseiroudoushou innaikansentaisaku sahbeiransu kensabumon dehta wo mochiita honpou ni okeru Listeria shou rikanritsu no suitei. IASR, 33, 247-248.

[16] Zamora, J. M., Chaves, C., \& Arias, M. L. (2006). Comparison of the antibiotics sensitivity pattern of Listeria monocytogenes and Salmonella spp. strains isolated from Food with clinical origin samples. Archivos Latinoamericanos de Nutrición. 56, 171-174. 